\title{
A Creative Expression of Celebrations: Rangoli
}

\author{
Dr. Meenakshi Thakur \\ Assistant Professor
}

Dept. Of Drawing and Painting, Faculty of Arts, Dayal Bagh Educational Institute,

[Deemed University] Dayal Bagh, Agra

Indian art has combined local tradition with outside influences, and has evolved along with a civilization, which has been remarkably innovative in all areas. The art has developed in the courts by the professional artists but folk art has developed in houses, worship places, courtyards, villages, among illiterate race. It is in fact an essential aspect of the celebrations in the family. India is a sub-continent and is composed of people with different cultures, different social customs and traditions and speaking different languages. Yet a stream of unity seems to run through the length and breadth of the country. It is this stream which in spite of all diversity keeps the country united. In Rangoli one can see the aesthetic expression of this unifying stream, with variation in styles and forms in different parts of the country. Rangoli is an Indian traditional - folk art, generally created on a floor on special festive occasions. The origin of this art can be traced to the "PURANAS". The tradition of Rangoli originated in Maharashtra state and slowly disseminated to other parts of India. Almost invariably these are practiced only by women and take the form of drawings on the floor or on the walls of the house reflecting their creative artistic expressions. Their style and quality depended on the materials available in the place in which they were executed, these very factors that helps to identify the region. In Maharashtra it is called Rangoli, Sathiya in Gujrat, Mandma in Rajasthan, Alpanan in Bengal, Chowkapurna in Madhya Pradesh, Chaitrangana in Maharashtra, Puvidal in Kerala, Muggu in Andhra Pradesh, Rangoli in Karnataka, Kolam in Tamilnadu, Ahapan in Bihar. This decoration is done in every home in the nook and corner of the country though the decorative shapes and designs differ from place to place. The aim is to worship and celebrate the spiritual and divine existence by making the designs beautifully.

The earliest Indian treatise on painting, the "Chitralakshana" mentions the legend of rangoli. In this legend, the son of a King's high priest died, and Lord Brahma, asked the king to paint the image of the boy so that he might revitalize him. The Chola rulers of India are recorded to have made extensive use of floor paintings And with that the art of floor painting came to life; and that is how the stone powder, rice four and flowers were transformed in to picturesque offerings to God in the form of floor painting. Vatsyayan, in his famous treatise on sex 'Kamasutra', has included Rangoli among the 64 arts enumerated by him. one find references to Rangoli in Sanskrit literature as old as 1050 A.D. Shri Abanindranath Tagore in his 'Banglar Brata' written in Bengali in 1919 focused on the vrata traditions of Bengal which was invariably accompanied with the ritual diagram alpana, the magical spells chhada and the corresponding katha. This pioneering work was followed by writings of Tapan Mohan Chatterjee, Mookerjee Ajitcoomar, Sudhansu Kumar Ray who wrote on the folk art of Bengal and threw some light on the art of alpana. Similarly in Rajasthan, works of Joginder Saksena, Ramgopal Verma covered some aspects of the Rajasthani 
mandanas. Lakshmikant Jha of Bihar, in his work on the folk culture of Mithila has written about the art of aripan.

The art of rangoli is one such form, prevalent all over India. It is seen that it is very much a living tradition in the cultural life of the country and is a permanent feature in festivals, marriages and other auspicious occasions. The folk art of rangoli does not belong to any particular period. It is the expression of the women themselves, since time immemorial. For untold generations they have delighted in an art which is collective, and has never attached any great importance to individual artistic talent. It is an art transmitted from generation to generation without any essential changes, the roots reaching deep into the soil. It is observed that women of all socio-economic levels continue to produce rangolis that even today hold particular guardian qualities and are placed before thresholds and on the floors inside the house. Rangoli still forms an indispensible part of festivals, religious and life sacrament rituals all over India. In the Southern states, particularly Tamilnadu and up to some extent in Maharashtra, drawing of rangoli remains a part of daily routine of the women.

The word Rangoli mean a row of colours. The colours used in this art are in powder form. White happens to the basic colour because of its easy availability. A woman usually creates these patterns bending over from the hips and allowing the rice flour or paste to flow from her fingertips just skimming along the ground, quickly discharging the material. During Diwali, women create rangoli in every corner of the dwelling space, with multiple auspicious designs, an escalation of patterning to parallel the escalation of festival of celebrations of lights.

As mentioned above, rangoli is practiced as a daily ritual in this part of the country, particularly Southern states and Maharashtra. Though rangoli is mainly drawn manually even today, supplementary devices have been introduced from time to time in the market. The reasons for the introduction of these devices is saving of time and attaining machine-made accuracy in the execution of the designs. As the females started going out of the house for work, the need to continue the daily ritualistic practices in shorter time laid to the invention of such devices. With new materials and devices for making instant rangolis thronging the markets, changes in techniques as well, are naturally visible.

In earlier days, the powder for rangoli was made from natural dyes. Today, synthetic rangoli powders are commonly used. The relatively long-lasting mediums like poster and oil paints is also commonly used nowadays. In Bengal, Rangoli is known as 'Alpana'. In Alpana, all lines start from a central point and then assume dainty, dynamic curves which ultimately produce different linear patterns. Alpana abhors straight lines and angles. Rabindranath Tagore's Shantiniketan in 'Bengal is trying to preserve and develop this art form. Apart from following the traditional designs of alpanas, the Kalabhavan of Shantiniketan makes new experiments in design - by synthesizing essential folk motifs with those of the modern decorative designs. Such combinations of

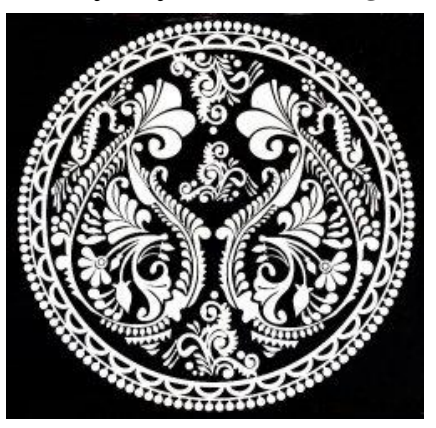

Figure 1. Contemporary Alpona apparently contradictory art forms have created a new vista in alpana tradition of Bengal.

The traditional Maharashtrian rangoli is linear in style with straight lines joining dots and forming designs. The art exists in the rural areas and up to some extent in the urban areas. The cities in 
Maharashtra, being particularly cosmopolitan in nature, all the types of rangolis are seen here. In Maharashtra, it was and still is a custom to draw a symbolic rangoli in front of the house in the mornings. The traditional style of rangoli designs in Maharashtra is geometrical. Designs are drawn by first making the dots and then joining them to make figures. These are then filled in uniformly with colours.

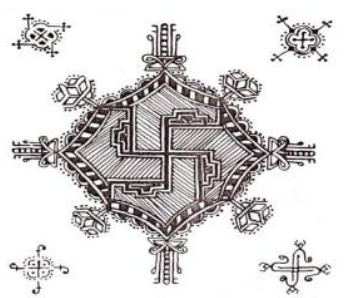

Sathiya

In Rajasthan rangoli is known as 'Mandana.' Apart from the floor, Mandana is drawn also on doors and walls. In Madhya Pradesh and Uttar Pradesh, one come across, 'Chowkapurna,' makes more effective use of squares. Rangoli in Gujarat is called Sathiya which itself means Swastika. Rangoli is drawn only on festive occasions here and the motifs are more of decorative nature consisting of flowers, birds and animals and ornamental designs. The decorative aspect is more focused upon than the ritualistic. However, on religious rituals, the Swastika motif is very popular. In Andhra Pradesh Rangoli is known as

Figure 4. Sathiya from Gujarat

'Muggu'. In Kerala, Rangoli is known as pookalam. Pookalams are laid out on festive occasion like Onam celebrations. This is rangoli made using freshly picked flowers and leaves of different kinds.

The art of rangoli has evolved over the period of time. The magical significance of the associated symbols has lost their importance, up to some extent. Today the art is expertly expressed in

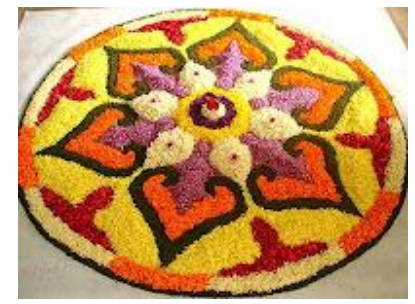

Figure 5. Pookalam from Kerala drawings that may be geometric, abstract, realist or figurative. It is the inheritance and artistic expression of the woman through their own techniques and symbols - prayers painted or 'written' from the heart. With the change in the socio-economic and religious values of the folk life, visual expression of folk imagination has considerably been changed, it is seen that the rangolis get a new meaning altogether, because of its acceptance in the modern society. It is noted that though the art of rangoli is constantly evolving in terms of material, techniques and style, the traditional method does not perish. The new form is accepted in keeping with the traditional practice. This is the reason behind its continuity and survival. Thus, reflecting regional beliefs and aesthetics based on a common spiritual plane the art of Rangoli is one which has survived all influences and retained and transmitted the spirit of Indian life.

\section{REFERENCES}

1. Chandra, Rai Govind. Indian Symbolism. New Delhi, Munshiram Manoharlal Publishers Pvt. Ltd., 1996

2. Chattopadhyay, Kamaladevi. Handicrafts of India. New Delhi, Indian Council for Cultural Relations, 1975

3. Dasgupta, S. (ed). Alpana. Kolkata,Publication Division, Government of India, 1975

4. Desai, Manu. To The Roots - A Designer's Journey. Mumbai, The Perennial Press, 1996

5. Huyler, Stephen P. Painted Prayers, Women's Art in Village India. London, Thames and Hudson, 1994

6. Jayakar, Pupul. The Forgotten Arts of India. New Delhi, Marg, September, 1969.

7. Pattanaik, Devdutt. Myth = Mithya. New Delhi, Penguin Books India, 2006.

8. Saksena, Jogendra. Mandana - A folk art of Rajasthan. New Delhi, Crafts Museum, 1985.

9. Shastri, Archana. The Language of Symbols, New Delhi, Crafts Council of India, 1977

10. Pratyaya, 1993, Kapil Tiwari, Madhya Pradesh Adivasi Lok Kala Parishad Bhopal.

11. P.K. Gode, 'History of Rangavalli Art between c. A.D. 50 and 1900', Studies in Indian Cultural History, Vol.III, Bhandarkar Oriental Research Institute, Poona, 1969, pp. 87-102. 